\title{
1. Policy analysis: roots and branches
}

The premise is simple, really. When government makes a decision that affects the lives of its citizens, it should carefully analyze the impacts of that decision before proceeding. But the implementation of this premise has proven over the past 50 years to be both far more complicated and far more controversial than the premise itself. In this book, I explore the question of why government analysis of its decisions is so challenging. It is my hope that an exploration of the analysis of government decisions will lead to ideas for better incorporating analysis into public sector decision-making, and thereby lead to better decisions.

Of course, not even the most stringent critics of analysis are suggesting that we should do no analysis of the impacts of government decisions. But structuring governmental decision-making in a democratic society requires great care. Ensuring that decisions are both responsive to the public will and reflect gains in the public welfare is a challenge that has been a continual struggle since the early republic. With many more public policy decisions now taking place in the unelected bureaucracy, the battle has taken on enhanced importance and a different character over the past several decades.

Much of the battle over the use of analysis in U.S. policy-making has taken place within the context of regulation. Regulations are issued by agencies of the executive branch of government or by independent commissions. They are issued pursuant to delegations of power from Congress, but these delegations are often vague, and leave critical policy choices to the regulatory agencies. Since the passage of a number of statutes in the 1960s designed to improve public health, clean up the environment, and enhance the protection of workers, the role of regulation has become a larger and larger part of policy-making in the United States.

With the increased importance of regulation has, not surprisingly, come growing attention to the subject. Those burdened by regulation have objected both to the regulations themselves, and their promulgation by unelected officials. Particularly in times of economic downturns (Coglianese et al. 2014), regulation has been blamed for rising unemployment and business failures. One common response to these 
complaints has been to require regulatory agencies to more carefully analyze the implications of their decisions (Shapiro and Borie-Holtz 2013).

This context has made regulation an excellent forum in which to study the role of analytical thinking in public policy. The breadth and variety of analytical requirements allow us to observe analysis in different forms and varying settings. In this volume, I look at cost-benefit analysis, risk assessment, environmental impact assessment, and other forms of impact assessment in the regulatory process. I provide examples of analysis having clear impacts on public policy decisions, and cases where it has either been ignored or failed to live up to its potential. Through these examples of when analysis works, and when it doesn't, I find trends in policy analysis that can inform further attempts to increase its role.

As we will see in the chapters ahead, several institutional factors are paramount in the role of analysis in policy-making. Political climates can facilitate the use of analysis or stifle it. Organizational factors such as the timing of analysis, and the placement in the regulatory bureaucracy of analysts, can also play a critical role. The legal structuring of analysis is also important, as exemplified by questions like: are analysts given a deadline, or, how does analysis interact with public participation and with judicial review in the formulation of policy decisions? Finally, the epistemic limits of science and social science, which questions can be answered and which ones cannot, are too often ignored in the practical debates over analysis.

The two questions that I hope to address successfully in this book are: under what circumstances have requirements for analysis in the regulatory process performed well (and when have they performed poorly), and what can we learn from the successes and failures of analysis as we contemplate efforts to adjust the role of analysis in policy-making? Some of these lessons will mirror those from the growth of the policy analysis discipline generally. Others will be new and different. Before we get to these discussions, however, there is a rich literature on the role of analysis in policy-making that informs this discussion. Academic scholars have long debated whether analysis should and could affect policy decisions, and what the long-term implications of an increased role for technocratic analysis are for democracy itself. I review that literature in this chapter. 


\section{ANALYSIS: ROOTS AND BRANCHES}

In his famous article, "The science of "muddling through," Lindblom (1959) contrasts two modes of policy-making. The first is comprehensive-rational analysis, where all policy options are considered, and the impacts of all options are evaluated, which then leads to a decision. He also dubs this the "root method." The second mode is incremental decision-making, that is, bureaucratic behavior where policy options are eliminated quickly as infeasible, and some potential impacts are not considered because they are irrelevant. He also calls this incremental form of decision-making, the "branch method." While the root method finds its theoretical roots in the then-burgeoning fields of decision science and welfare economics, the branch method is reflective of the bounded rationality school of Herbert Simon. ${ }^{1}$

Lindblom argues that while on the surface comprehensive-rational decision-making appears to be superior, it is impossible to achieve. To truly consider all of the impacts of all possible alternatives is impossible, and even if it were possible it would take years to do so successfully. "In actual fact, therefore, no one can practice the rational-comprehensive method for really complex problems, and every administrator faced with a sufficiently complex problem must find ways drastically to simplify" (Lindblom 1959, p. 84). Meltsner (1976) notes that the goal of the analyst is to be only 90 percent right, but Lindblom would probably see this figure as impossibly high as well.

In contrast, the branch method is a useful way of making decisions simpler.

Since the policies ignored by the administrator are politically impossible and so irrelevant, the simplification of analysis achieved by concentrating on policies that differ only incrementally is not a capricious kind of simplification. In addition, it can be argued that, given the limits on knowledge within which policymakers are confined, simplifying by limiting the focus to small variations from present policy makes the most of available knowledge. (Lindblom 1959, p. 85)

Hence, according to Lindblom (1959, p. 86), incremental modes of decision-making are in fact superior to attempts to impose a comprehensive assessment of the impact of policy options.

[F]or all the apparent shortcomings of the incremental approach to policy alternatives with its arbitrary exclusion coupled with fragmentation, when compared to the root \{comprehensive\} method, the branch method often looks far superior. In the root method, the exclusion of factors is accidental, 
unsystematic and not defensible by any argument so far developed, while in the branch method, the exclusions are deliberate, systematic, and defensible.

Lindblom $(1968,1979)$ expanded on his assessment of the root method in his book, The Policy-Making Process and in several articles. He lists four reasons why analysis does not influence policy in the way hoped for by its advocates. First, analysis cannot help but be fallible and consumers of analysis know it.

No educator fully understands how children with widely varying backgrounds and personalities should be taught to read. Economists do not know enough to cope very well with simultaneous inflation and unemployment ... The choice between synopsis and any form of strategic analysis is simply between ill-considered, often accidental, incompleteness on one hand and deliberate designed incompleteness on the other ...

Analysis is also fallible in more blatant ways in that much of it is poorly informed, superficial or biased - not infrequently making shoddy attempts to prove by specious means what someone in power has already decided to think. (Lindblom 1979, p. 519)

Or as Meltsner (1976, p. 268) put it, "a central problem for analysis is not knowing much."

Second, analysis is incapable of resolving conflicts in values. There is no single criterion by which to convince those who lose because of policy choices to support those choices. Third (echoing his earlier concern), analysis is too slow and costly. Finally, analysis cannot be used to determine which problems to tackle.

This framework has been extended considerably in the more than half-century since Lindblom first wrote. Notably, Lindblom's work has been more closely tied to Simon's theories on satisficing as a decisionmaking alternative to comprehensive-rationality. Simon (1972) argued that individuals do not consider all options (as an advocate of comprehensive-rationality would want them to), but rather they sift through options until one that meets certain minimal criteria is found. Others argue that advocates of analytical requirements assume that presented with the results of analysis, decision-makers will act rationally, and that this is a particularly unrealistic assumption (Cashmore et al. 2004 (the authors are particularly concerned with environmental impact statements)).

Forester (1984) further illuminated Lindblom's argument. While noting the theoretical desirability of comprehensive-rational analysis, he noted a series of obstacles to its actual implementation. The first of these was the cognitive limits on individual decision-makers described by Simon. The 
second limit was the fact that multiple decision-makers, even those who agree on goals, may have different skills and insights. The third obstacle is that parties will disagree on political goals and that will affect their ability to rationally analyze policy questions. Finally, these differences do not necessarily represent a pluralist cacophony of views but rather the fact that often some powerful voices speak loudest and drown out others.

Forester concludes (p. 30),

Technical solutions depend on a stable context and a problem to be solved that can be isolated from that context. Practical solutions depend upon the particularities of the context at hand that define the given problem. Being practical means being responsive to the demands made in a given situation with all of its instabilities ... Thus being technical and being practical may well be two very different enterprises.

Sidney A. Shapiro (2011) also draws on Simon and the organizational design literature to argue that regulatory agencies have deliberately structured their decision-making processes in a way that shows they wish to avoid a comprehensive-rational approach.

Analysis is not without its defenders. Many see the comprehensiverational analysis end of the spectrum as a straw-man and assert that the goals of analysis are not comprehensive but rather incremental in their own way. Taylor (1984), describing environmental impact statements (EISs) (the subject of Chapter 5), argues that the goal of EISs and similar requirements is to work toward incorporating the "science model" of decision-making into the conflict-laden world of politics. He goes on to argue that process changes should be judged by whether they make agreement easier, in addition to whether they lead to better policies.

Analysis has been widely praised as increasing the transparency of governmental decision-making on complex issues (Sunstein 2002). Advocates of analysis have claimed that laying out the consequences of governmental action improves the ability of the public to weigh in on these actions, either directly or through their elected representatives. Rayner (2003), however, argues that these analyses themselves are hopelessly complex and therefore it is nonsensical to claim that they improve transparency. In fact, analysis has served to further deter public participation in government decisions. "Those who understand the modeling techniques, then, can wage debate over ideological issues under the guise of impartial analysis - distorting and submerging the real issues of importance" (Jenkins-Smith 1990, p. 69). 


\section{EXPERTISE AND DEMOCRACY}

In many ways, the debates over comprehensive-rational analysis are part of a broader (and older) debate over the tension between expertise and democracy. Plato argued against democracy citing its tendency to undermine expertise (Christiano 2015). Imposing analytical requirements on public policy-making has been seen both as a way of solving the tension between expertise and democracy, and exacerbating it.

The nature of science (and even more so of social science) is such that manipulation of science is always a possibility. The questions that policy-makers ask scientists or economists are ones with uncertain answers. Such uncertainty can give elected officials or agency bureaucrats room to question conclusions and the assumptions that went into the models that led to those conclusions (Rushefsky 1986). "It is now recognized that the questions regulators need to ask of science cannot in many instances be adequately answered by science" (Jasanoff 1990, p. 7).

As a result, the debate over the use of expertise in public policymaking has become as polarized as debates over the policy issues themselves. Some worry that government experts are imposing their own preferences, and hence undermining democracy. This worry can come from those who assume government bureaucrats are obsessed with their missions and intent on over-regulating industry, or from those who believe that government experts are "captured" by industry experts and are under-regulating industry. Open or participatory decision-making is often touted as the solution to these problems (Jasanoff 1990). Ironically, analysis is also seen as a check against the tendencies of bureaucrats to either be captured by outside interests or to impose their own ideological preferences (Katzen 2007).

Jasanoff (1990) criticizes both a technocratic approach which looks to scientists for validation of policies in technical areas, and a view that democratic or participatory oversight is needed to counteract the biases of experts. She characterizes the debate over scientific expertise as polarized between those who believe that expertise is inherently biased and therefore fair game for manipulation by political actors, and the view that expertise is inherently superior to popular input. The solution according to Jasanoff is accountability for experts, both to peers within their disciplines, and to the public at large (Jasanoff 2003).

Renn (2008) describes three modes of governmental decision-making into which analysis (he is discussing risk assessment - the subject of Chapter 4 of this book) can fall. The "technocratic mode" is one in which scientists make the key decisions about appropriate risk levels. In the 
"decisionistic mode," science is one input into policy decisions. The third mode is the "transparent (inclusive) governance mode" where "science, politics, economic actors, and representatives of civil society are invited to play a role in both assessment and management" (Renn 2008, p. 11). Renn's work clearly favors the third mode as the preferred way of public decision-making.

Without some means of accountability, the fear emerges that analysis (or other forms of expertise) often plays a role in supporting decisions made by other means. This fear goes back to the earliest days of policy analysis. Meltsner (1976) describes analysis of Supersonic Transport (SST) in the 1970s. His interview subjects, policy analysts at the Department of Transportation (DOT), "described their role as "strictly to support the SST." This supportive role is more problematic when analysis is described as playing a role in decision-making but instead is constrained to a particular solution (Wagner 2010a). Wagner (1995) also describes the "science charade" where decisions made based on values are cloaked in the veil of science in order to increase their legitimacy.

In summation, analysis has been seen as undermining democratic decision-making for two reasons. First is Wagner's science charade which could be more broadly classified as an analysis charade; policy-makers declare their decisions as based on comprehensive analysis, thereby muting criticism of policy made because of choices grounded in values. Second, and contradictorily, advocates of democracy have long feared the Platonic ideal, decisions that are made by unelected technocrats who have no accountability to the public.

Despite these persistent fears comprehensive-rational analysis continues to have an appeal. "Nothing that Lindblom or his colleagues had to say about the limits to rationality diminished the advocacy of comprehensive decision-making methods" (Atkinson 2011, p.9). Some of that appeal is cynical. There is an undeniable appeal to selling your preferred policies as supported by rationality (or science or economics). This is true for politicians, advocates and bureaucrats. "Today what we are left with is ... rationalism as a form of symbolic politics that various bureaucratic entities use to project the 'illusion' of rationalcomprehensive decision-making as a strategy to legitimize the exercise of political power" (Saint-Martin and Allison 2011, p. 19).

But some of that appeal is also genuine. As policy problems become more and more complex, the attraction of expertise as a means of solving those problems increases. Attempts to require more forms of analysis have proliferated (Shapiro and Borie-Holtz 2013). To evaluate these attempts we need to better understand how different forms of the "comprehensive-rational analysis" criticized by Lindblom have operated 
in practice. Very little of the literature on analysis in public policy is empirical, most of it is philosophical. This book attempts to help correct that imbalance.

\section{A VERY BRIEF HISTORY OF THE USE OF COMPREHENSIVE-RATIONAL ANALYSIS}

While the debate over expertise goes back centuries, we can date the modern debate over analysis to the 1960s. The use of comprehensiverational analysis finds its roots in the efforts during the Great Society to apply the techniques pioneered by Secretary of Defense, Robert McNamara, at the Defense Department to guide social policy. "These developments in the social sciences - particularly systems analysis and operations research - largely moved along two pathways: positivism (using the concept of laboratory experiments to differentiate the true from the false) and normative economic reasoning based on the concept of the market" (Radin 2015, p. 4). The goals in the early years of analysis were extremely ambitious. One observer wrote, "the analysis of rational program choice is taken as the one legitimate arbiter of policy analysis. In this mood, policy studies are politically deodorized - politics is taken out of policymaking" (Heclo 1972, p. 101).

Advocates for policy analysis were not blind to its potential failings. One of the most ardent advocates, Yehezkel Dror, argued that numerous preconditions were necessary in order for the policy sciences to succeed. These included political actors who were both more capable of understanding policy analysis and dealing with reasonably presented alternatives, and a public that was sufficiently well-informed to take advantage of policy analysis. He was optimistic that these conditions could be achieved (Dror 1971).

One of the first ${ }^{3}$ and most famous manifestations of comprehensiverational analysis was the use of the Planning, Programming, and Budgeting System (PPBS) which began with Secretary of Defense McNamara. Even in the Defense Department, verdicts on the influence of systems analysis and PPBS were mixed. Some reviewers found the influence was significant while others argued it was minimal (Nelson 1987). As PPBS was expanded by President Johnson to social service agencies, the challenges mounted and the Nixon Administration quickly abandoned the technique for rationally determining program budgets (Wildavsky 1974).

Wildavsky (1974) described a series of case studies of the role of PPBS and found that in no instance had the technique successfully influenced budgetary decisions. "PPB was implemented in form but not 
in substance" (Wildavsky 1974, p. 197). In describing the process that agencies and the Bureau of the Budget followed he says, "they produce a vast amount of inchoate information characterized by premature quantification of irrelevant items ... Its very bulk inhibits understanding. It is useless to the Director of the Budget in making his decisions" (Wildavsky 1974, p. 202). Why did PPBS fail? The most common argument laid the blame at the feet of politics and bureaucracy, factors that will appear repeatedly in this book. Congressional committees saw power going to executive branch and therefore objected to PPBS. PPBS also required more centralized control than was possible in civilian agencies (in contrast to McNamara's Defense Department). Individual agencies were not willing to give up control to more centrally located entities (Jenkins-Smith 1990).

These arguments, blaming politics and bureaucracy for the failure of PPBS, were prevalent in autopsies of PPBS. In contrast, Wildavsky maintained that failure was inevitable, "Failure is built into its very nature, because it requires ability to perform cognitive operations that are beyond present human (or mechanical) capacities" (Wildavsky 1974, p. 206). This echoes Lindblom's fears from a decade and a half earlier and Simon's arguments on bounded rationality. The limits to the amount of information that humans or organizations can process lead to limits to what analysis can tell us.

So comprehensive-rationality left the budget process. But in its wake it created a new field, policy analysis. Wildavsky (1969) himself had hopes that policy analysis could be "rescued" from PPBS. According to Wildavsky analysis works better on questions that are more circumscribed where alternatives can be meaningfully addressed.

Numerous works have talked about the growth of policy analysis in the federal bureaucracy. Lynn (1989) argued that policy analysis was not a radically new phenomenon but rather one that has always been part of government decision-making. Echoing Lindblom in part he argues that sophisticated analysis has at most a marginal effect on policy. He does give the spread of policy analysis credit, however, for expanding the perspectives available to policy-makers. Williams (1998) laments the decline of the influence of policy analysis over its first three decades. ${ }^{4} \mathrm{He}$ cites the politicization of analysis, particularly during the Reagan Administration. He blames the increasing influence of the Executive Office of the President, "Honest credible information, sound policy analysis ... have never been so difficult to develop than in today's political climate of limited executive branch demand and rising public distrust and cynicism about the federal government and its numbers" (Williams 1998, p. 22). Jenkins-Smith was also pessimistic about the role of policy analysis, 
"Analysis supports the status quo, not significant change. Repeated studies have shown that despite the increased provision of analyses, those analyses have little direct effect on policy formulation" (Jenkins-Smith 1990, p. 47).

While these works are important for the topic of this book, they largely talk about how policy analysts have evolved from the comprehensiverational analysts envisioned by Lindblom as a result of bureaucratic and political factors (Meltsner 1976; Jenkins-Smith 1990; Radin 2013). The field of policy analysis began its evolution in comprehensive-rational analysis but now includes program evaluation, policy mapping, and many other techniques (Radin 2013).

But many of the requirements placed on regulatory decision-making are clearer reflections of the more unadulterated and more comprehensive form of analysis. Cost-benefit analysis, impact analysis, and risk assessment, fall on the comprehensive-rational end of the spectrum of policy analysis. These requirements remain in place, and more are regularly proposed both on the federal and state levels (Shapiro and Borie-Holtz 2013).

Comprehensive-rational analysis is often conflated particularly with economic analysis. And indeed, as I explore in Chapter 3, economic analysis is clearly the favorite son of comprehensive-rational analysis and McNamara's "whiz kids." However, the idea that a policy problem can be thoroughly analyzed and an optimal solution produced is not unique to economics. Supporters of the natural and physical sciences in particular have often claimed that policy issues could only profit from their perspective. This is particularly true when such issues involve interaction with the physical world in policy areas such as risk reduction and environmental destruction.

Hence while policy analysis has broadened beyond its comprehensiverational origins, pure comprehensive-rational analysis (or mostly pure) is alive and well. It is alive in the application of welfare economics, risk assessment, and environmental impact assessment to the regulatory process. It also has a not-that-distant offspring in the many other forms of impact analysis that regulators are required by statute and executive order to conduct.

\section{FACTORS INFLUENCING THE EFFECTIVENESS OF POLICY ANALYSIS}

Both the theoretical work by Lindblom and others, and the work on the history of policy analysis as a discipline provide numerous candidates for 
factors that determine whether analysis makes a real difference in policy decisions. Chief among these are factors related to politics and bureaucracy. As mentioned above, many attributed the failure of PPBS to reluctance among politicians and among bureaucrats to surrender power to analysts (Jenkins-Smith 1990, but see Wildavsky 1974).

The academic widely credited with creating the environmental impact statement (the subject of Chapter 5) emphasized the role politics has played: "But policy decisions are more often shaped by political expediency, and less often based upon objective scientific estimates of probabilities. Impact assessment involves both science and art and cannot avoid implications for priorities among values. Hence to some degree it is, in the better sense of the term, a political process" (Caldwell 1991, p. 84).

It is important to resist the temptation to reduce the roles of both political actors and of bureaucrats to caricature, however. The debate over the failure of PPBS contained some such caricatures. Politicians were reluctant to embrace analytical results that contradicted their preferred policies (or the preferred policies of their constituents or favorite interest groups). Bureaucrats also feared analysis both because of their own policy preferences and because of a general reluctance to change or cede power. These stereotypes, however, are not terribly useful and, like many stereotypes, likely vastly oversimplify the reaction of decision-makers to the imposition of analytical requirements.

It is far more useful to ask which factors within a political environment and which factors associated with organizational structure are more conducive to accommodating analytical thinking. Political environments have been spliced many different ways in the political science literature. They can be characterized as "high salience" or "low salience" depending on the level of interest in the issue at hand (RePass 1971). They can be characterized by the complexity of the issue (Gormley 1986). They can be characterized by whether the costs and benefits of a policy decision are concentrated in a small number of parties or a large number of parties (Wilson 1980).

Any of these and numerous others could play a role in the receptiveness of political actors to analytical results. As will be detailed in Chapters 3-6, many proponents of analysis have largely seen political concerns as undermining analytical ones (e.g. National Research Council 1983; Taylor 1984; Hahn and Tetlock 2008): "The literature in the policy analysis field is replete with illustrations of conflict between the two cultures. Most frequently, the dichotomy is established as a conflict between analysts and politicians. It is also defined as a conflict between intelligence and power, and between studying and action" (Radin 2013, 
p. 125). However, some of the types of analysis, specifically environmental impact statements and small business impact statements, may give particular interest groups (environmental groups and small businesses respectively) additional tools with which to advocate their causes. This may make these types of analysis more effective, and by explicitly and deliberately intertwining analysis and politics it makes the discussion of analysis much more complicated.

Politics and the legal standing of analysis interact in varying ways. As we will see in Chapter 3, cost-benefit analysis of regulations in the federal government is attached to review of regulations by the President. This ties cost-benefit analysis to the political preferences of the President, and may compromise its effectiveness as a policy-making tool (Arbuckle 2011). On the other hand, environmental impact analyses are judicially reviewable according to the statute which mandates them, the National Environmental Policy Act (NEPA). Judicial review has had mixed effects on the role of environmental impact statements in policy-making (Taylor 1984).

The interaction between bureaucratic organization and the use of analysis has also received considerable attention. Taylor (1984), in a study of the Army Corps of Engineers and the Forest Service, argued that numerous characteristics of agencies determined whether environmental impact analyses were effective. These included the level of knowledge about the subject material in the agency, the interest group environment, and the organizational structure. Jenkins-Smith (1990) also listed three bureaucratic factors, but his three were: the level of conflict over the issue, the level of "analytical tractability" (is there an answer?), and the openness of the decision-making environment. The last of these three is particularly interesting as Jenkins-Smith argued that the more open the forum, the more likely it is that analysis will be used for political means. This argument runs counter to that which argues that one of the chief benefits used to justify analysis is increased transparency.

Bureaucratic factors also interact with the legal setting of analysis, particularly with regards to this question of transparency. In some contexts, particularly risk assessment, there have been calls for increased participation in the process of regulatory analysis. The environmental impact assessment literature is rife with paeans to the necessity of participation in order to make environmental impact statements work. This interaction, however, has largely escaped empirical analysis (Glucker et al. 2013).

In addition to the nature of participation, scholars have also emphasized the location of analysis within the policy-making process. Taylor (1984) focuses on it and notes the trade-off between giving analysts an 
independent voice or integrating closely with political decision-makers, "we do not want the analysts to be integrated and influential at the cost of being co-opted, nor do we want them to be so autonomous as to be irrelevant to policy decisions" (Taylor 1984, p. 94). He goes on to note that the analysts themselves preferred independence, "The analysts" greatest fear was dispersal into other functional units. Dispersal would decrease their influence, put them under closer supervision, reduce their specialization, and hinder their ability to allocate their resources according to their own priorities" (Taylor 1984, p. 110).

Meltsner interviewed many policy analysts early in the 1970s, as the field was growing. He noted that many early policy analysts went into federal service hoping to influence the bureaucracy but ended up instead being influenced. "Some analysts adjust to the bureaucracy by becoming bureaucrats while others adhere to the norms of their former professions" (Meltsner 1976, p. 17). He also found that many of his interview subjects had grown frustrated at agencies because of the many layers of review that their work had to pass through before being seen by decisionmakers. These layers of review also vary from organization to organization.

Robert and Zeckhauser (2011) describe a spectrum of policy analyst archetypes. Policy analysts range from the dispassionate analyst who puts aside values, favors transparency, and carefully calculates policy impacts, to the analyst-advocate who embraces the value laden aspects of political decisions and sees analysis as one component of those decisions. They argue that the presence of even a small number of analyst-advocates leads to the contagion of strategic behavior among all types of analysts (Robert and Zeckhauser 2011).

These works give us several institutional factors that need to be a part of any discussion of the role of analysis in policy-making. Scholars have identified the political climate of the policy decision at hand, the placement of analysis within a bureaucracy and how it fits within the bureaucratic culture, and how analysis is restricted or enabled by legal requirements as key factors. The questions raised by Lindblom (1959) and Wildavsky (1974) point not to the environment in which analysis takes place but rather to the nature of analysis itself, the degree to which it can answer the questions that policy-makers ask it, as a (if not the) critical determinant of the role of analysis. As I present the varying types of analysis in Chapters 3-6, I will highlight the roles of these four categories of institutional constraints. 


\section{ANALYSES OF ANALYSIS}

Lindblom framed his criticism of comprehensive-rational analysis in rather absolute terms. The root method for analyzing policy questions is, as even Lindblom tacitly acknowledges, something of a straw-man. If agencies were really required to perform a truly comprehensive analysis, no policy decisions would ever be made in the executive branch. Yet, the continual attempts to impose new analytical requirements on policy decisions reflect a lasting appeal of moving in the direction of a "root" method.

There are many possible reasons for this. Critics of analysis ascribe the desire for root methods in cynical terms. They note that the supporters of analytical requirements often overlap considerably with those who oppose government intervention in the marketplace for self-interested reasons. Hence they argue that proponents of analysis do not want comprehensive-rational analysis per se; rather they want to slow down the regulatory process and make it harder for agencies to issue regulations (McGarity 1992).

The legal system also has played a role in the continual ratcheting up of analytical requirements. In the regulatory world, agencies operate in an adversarial environment (Kagan 2001). Few regulations of significance come without opponents ready to challenge the legality of the agency's action. Any analysis required of the agency can get pulled into a subsequent legal proceeding, whether or not the analysis itself is part of a judicially reviewable requirement. This legal environment creates the incentive for the agency conducting the analysis to be as thorough (or as comprehensive and rational) as possible, in order to avoid the possibility of losing a lawsuit because their analysis is "arbitrary and capricious."

Of course some of the motivation for putting requirements in place for comprehensive-rational analysis should also be taken at face value. As stated at the outset, there is an inarguable appeal to carefully laying out the implications of various policy choices and selecting the "best" one. Even if it is impossible to select the best choice, surely a decisionmaking process with more analysis will lead to a better choice than one with less analysis. Every attempt to enshrine the root methods of policy determination is accompanied by many who argue from a true faith that these methods will improve policy decisions.

Lindblom's argument about comprehensive-rational analysis is both positive and normative. The normative argument about analysis continues unabated and hopelessly colors perspectives on the positive one. Those who feel analytical requirements are unethical or bad for democracy cite 
policy decisions that stretch out for decades (McGarity 1992). Those who feel analytical requirements are necessary for policy decisions that are increasingly complex cite policy failures that would have been easily avoided if only more analysis had been done (Winston 2007).

Empirical work on the actual role that the various forms of comprehensive-rational analysis have played in policy decisions is limited. Meltsner's work (1976), described above, which looked at the early days of policy analysis and some of the work on PPBS are still among the best pieces of work around but they are now nearly 40 years old. Radin (2013) has also explored the shifting role of the policy analysis discipline and has added significant insights. Finally, within the regulatory arena, several scholars have looked at the particular types of analysis covered in this volume and how they affected individual regulatory decisions. I summarize this literature here and review it in more detail in Chapters 3-6.

Morgenstern and Landy (1997) assemble 12 cases of cost-benefit analysis at the Environmental Protection Agency (EPA). They found that analysis did improve regulatory decisions but it did not have nearly the influence hoped for by advocates. Unlike the focus on politics and bureaucracy in the broader literature, their conclusions focus more on qualities of the analysis itself. In particular, they note how the inherent uncertainty in cost-benefit analysis renders it less useful to decisionmakers. Uncertainty is also a key player in Graham et al.'s (1991) examination of risk assessment in decisions whether to regulate emissions of formaldehyde and benzene. In the case of both chemicals, different agencies reached different decisions at different times, again showing the limitations of a form of comprehensive-rational analysis.

Taylor (1984) uses EISs to assess efforts at "Making Bureaucracies Think." He wraps in many of the themes mentioned here - politics, bureaucracy, limitations inherent to analysis - and he also brings up other factors that will be discussed in the chapters that follow, such as the legal structure in which analysis is conducted and the role of individual personalities, both analysts and decision-makers.

Requirements for analysis are inherently procedural in nature. Indeed they are often put in place because of difficulties in getting agreement on the substantive goals which they embody (economic efficiency, environmental sustainability (Cashmore et al. 2004)). Hence many of the empirical evaluations of the literature are also procedural. The works described in the paragraphs above are the rare exceptions that attempt to grapple with the substantive impacts of analytical requirements. I hope that this volume adds to this assessment. 
This is not to dismiss the importance of procedural evaluations. Analytical requirements can and should be judged on these terms as well. However, five decades in to the experience of placing analytical requirements on public agency decision-making processes, we continue to focus on procedure almost exclusively. At the very least, we should know more than we do about when these requirements lead to changes in public policy, what these changes are, and under what circumstances analysis leads to changes.

\section{ROOTS AND BRANCHES AGAIN}

In this book, I hope to grapple with the positive implications of Lindblom's arguments on comprehensive-rational analysis. Can analysis work in our governmental system, and, if so, under what conditions? Many of Lindblom's critics focus on his defense of incrementalism in policy-making (see e.g. Bendor 1995). This book is intended neither as a defense nor a criticism of incrementalism. Instead I am focusing on another critical claim of Lindblom's. Lindblom argues that comprehensive-rational decision-making is not only undesirable but is in practice impossible. This is true whether the changes from the status quo are large or small. It is impossible to analyze all (or most) of the consequences of a policy change. This contention has important implications for how we make policy.

Forester (1984) argues that comprehensive-rational analysis requires: 1) a well-defined problem, 2) a full array of alternatives to consider, 3 ) full baseline information, 4) full information about the consequences of each alternative, 5) full information about the values and preferences of citizens, and 6) full adequate time, skill, and resources. Like Lindblom, these requirements reduce comprehensive-rational analysis to a caricature. But does their impossibility of achievement mean that we must abandon all hope of analysis in policy-making? Does their impossibility render analysis as a fundamentally political tool that will inevitably be manipulated to political ends? ${ }^{5}$ One aim of this book is to look at the regulatory process and understand where the impossibility of these prerequisites has thwarted efforts at informing decisions with analysis and where they have not.

In a sense, the focus on the comprehensiveness and rationality of different forms of policy analysis has obscured their potential usefulness. Advocates of analysis find themselves defending the root method of policy analysis while critics mercilessly try to pull up those roots. But many movements toward better policy analysis are really about building 
better branches. Lindblom (1959) himself argued that analysis should look at marginal differences between policy changes and the focus should be on a small number of policy alternatives. Few advocates of analytical requirements would disagree with this premise (Carrigan and Shapiro 2014).

As the chapters ahead will show, the attempts to use comprehensiverational analysis in the regulatory process can teach us about the effectiveness of even small steps in that direction. It also helps us evaluate attempts to impose comprehensive-rationality on the regulatory process today. Just as Lindblom advocates incrementalism in policy change, the impacts of analytical requirements have largely been incremental in character.

Requiring agencies to undertake some form of comprehensive-rational analysis may have other effects on policy decisions. Analysis could affect decisions more in the long run than in the short run (Cashmore et al. 2004). Embedding analysts within the bureaucracy can change the culture of an agency so it is more inclined toward analytical thinking. It can empower external parties which support analytical thinking (or the underlying goals of the analytical requirements) (see also Taylor 1984).

This book suggests that the broadest fears and greatest hopes associated with comprehensive-rational analysis have not been realized. We have not evolved (or degenerated, depending on your point of view) into a technocratic state where analytical thinkers systematically override the will of the people as some had feared (Jasanoff 1990; Jenkins-Smith 1990). ${ }^{6}$ Policy-making in the executive branch (where analytical requirements are prevalent) has not been frozen in its track paralyzed by analytical requirements. But neither have policy decisions become markedly more economically efficient, more environmentally rational, or prioritized according to the level of risk.

Yet, the chapters ahead provide numerous examples of cases where cost-benefit analysis, risk assessment, environmental impact assessment, and other impact assessments have made a difference. Some made marginal improvements. Others involve avoiding decisions that analysis has shown to be particularly poor. Still others promote the goals of particular groups such as environmentalists or small businesses whom specific kinds of impact analysis are designed to empower.

As policy-makers contemplate implementing more and more requirements for analysis, it is time to step back and think about the impacts of existing requirements. There is a need for greater modesty when selling the possible accomplishments of analysis. We need to reframe analytical requirements to help decision-makers rather than drive decisions, and to discern when analysis works and when it doesn't. When does it succeed 
on its own terms by making policy decisions better? When does it facilitate democratic decision-making? When can it subvert it?

Briefly, the rest of the book proceeds as follows. In Chapter 2, I review the history of analysis in the regulatory process over the past 40 years. Chapters 3-6 form the bulk of my research on analysis in the regulatory process. These chapters include descriptions of the analytical requirements and the literature on these requirements. I then proceed to describe my interviews with nearly 50 analysts who have collectively worked on analyses of thousands of regulatory issues. Then in each chapter, I describe between one and three cases, including examples of where each type of analysis has succeeded and where it has failed. In Chapter 3, I discuss cost-benefit analysis; in Chapter 4, risk assessment; in Chapter 5, environmental impact assessments; and in Chapter 6, the many other forms of impact assessment required of regulators.

In Chapters 7-9, I present my conclusions from this empirical research. In Chapter 7, I synthesize the results of the case studies and the role that politics, bureaucracy, and law played in these cases. I suggest possible reforms that would improve the relationship between analysis and policy-making in Chapter 8. In Chapter 9, I offer my concluding thoughts. The field of policy analysis is a young one, perhaps just entering its adolescence. We are just now getting a sense of what it can and cannot do. My hope is that this book will help us understand how to better ensure that analysis in the policy process can reach its potential while also better understanding its limitations.

\section{NOTES}

1. Simon argued that economists and political scientists who depended upon rationality for their conclusions were dependent upon a false premise. Simon said that rationality was bounded and that individuals (including government officials) engaged in searches to find preferred choices. The searches concluded when an option that was satisfactory was found. This work has been greatly expanded upon in the decades since (Simon 1972; Forester 1984).

2. Nelson (1987) argues that the roots go even deeper. He traces the fascination with analysis back to the progressive movement of the early 20th century. While many others have moved on from the progressive idea that administration could be separated from politics and optimized, advocates of analysis, particularly economists continue to be influenced by this idea. Radin (2015, forthcoming) traces the history to debates over the use of science in policy after World War II featuring Vannevar Bush and Robert Oppenheimer.

3. Porter (1996) argues that the use of cost-benefit analysis in the Army Corps of Engineers from the 1930s through the 1950s is the crucial antecedent to the growth of comprehensiverational analysis. I discuss the Army Corps experience in Chapter 3.

4. This theme was echoed in the 2014 President's Address before the Association of Public Policy Analysis and Management conference by Professor Angela Evans. She harkened back to a time when policy analysts contributed to debates and there was, "engagement by 
a wide array of players, an understanding that perfection was not possible, and a commitment to keep watch over policies as they moved into implementation" (Evans 2015, p. 258).

5. Caldwell (1991) describes analysis as "vulnerable to definitional card-stacking."

6. This fear has not disappeared, it can still be found in the rhetoric of the Tea Party. 